\title{
Como a Prática Esportiva Inclusiva na Escola Pode Contribuir na Vida Social do Aluno?
}

\author{
How can Inclusive Sport Practice at School Contribute to the Student's Social Life?
}

\author{
Celina Lopes*ab; Rafael Fernando Pereira de Oliveira ${ }^{a}$; Gildiney Penaves de Alencar ${ }^{\text {ac }}$ \\ anstituto de Educação e Pesquisa Alfredo Torres, Pós-Graduação em Educação Física Escolar e Inclusiva. MS, Brasil. \\ bPrefeitura Municipal de Campo Grande. MS, Brasil. \\ cPrefeitura Municipal de Campo Grande, Rede Municipal de Ensino de Campo Grande. MS, Brasil. \\ *E-mail: celinalopeskef@gmail.com
}

\begin{abstract}
Resumo
A escola, enquanto espaço de formação, tem como função social transmitir o saber sistematizado e fornecer acesso para as mais distintas áreas do conhecimento, entre essas a Educação Fìsica, a qual tem como objeto de estudo o corpo em movimento e possui uma função social a cumprir em toda a Educação Básica, inclusive, as práticas esportivas presentes nas aulas. Dessa forma, o objetivo deste estudo é comp reender como a prática esportiva inclusiva, na escola, pode contribuir para a vida social do aluno, por meio de uma revisão integrativa de artigos publicados de 2010 a 2020 nas bases de dados: Lilacs, SciELO, DOAJ e Dialnet através das combinações dos descritores exatos e sinônimos, em português e em inglês, pelos termos: "esportes", "inclusão" e "escola". A busca resultou em uma amostra final de dez artigos e permitiu observar que há um consenso entre os autores de que a prática esportiva contribui, significativamente, com a inclusão dos alunos no meio social, já que ocorrem interações que podem ser levadas ao contexto comunitário, porém, ainda assim, existem autores que não acreditam que isso aconteça, além de poucos estudos que tratem da temática "inclusão", portanto, digna de ser amplamente explorada. Como contribuições, o estudo sugere que pesquisas futuras possam partir para o campo da mensuração para complementar as conclusões qualitativas, além disso, pode servir como reflexão para os estudiosos encontrarem caminhos que ampliem o conhecimento acerca do assunto.
\end{abstract}

Palavras-chave: Esportes. Inclusão. Escola.

\begin{abstract}
The school as a training space has the social function of transmitting systematized knowledge and providing access to the most different areas of knowledge, among them Physical Education, which has the body in motion as its object of study and has a social function to fulfill throughout basic education, including sports practices present in classes. Thus, the aim of this study is to understand how inclusive sports practice at school can contribute to the student's social life through an integrative review of articles published from 2010 to 2020 in the Lilacs, SciELO, DOAJ and Dialnet databases through combinations of the exact and synonymous descriptors in Portuguese and in English by the terms "sports", "inclusion" and "school". The search resulted in a final sample of 10 articles and allowed us to observe that there is a consensus among the authors that sports practice contributes significantly to the students' inclusion in the social environment, since that interactions occur that can be taken to the community context, even though, there are authors who do not believe this happens, in addition to the few studies that deal with the theme "inclusion", therefore, worthy of being widely explored. As contributions, the study suggests that future research may move into the field of measurement to complement qualitative conclusions, in addition, it can serve as a reflection for the students to find ways that expand knowledge on the subject.
\end{abstract}

Keywords: Sports. Inclusion. School.

\section{Introdução}

O esporte possui estreita relação com a educação, processo utilizado com o intuito de formar o cidadão, presente em todas as sociedades humanas e faz parte dohomem como ser social e histórico. Para Tubino (2011), o esporte possui significação social, pois é um meio de socialização; favorece o desenvolvimento da consciência comunitária, por ser uma atividade essencialmente coletiva;é uma atividade prazerosa; proporciona coesão social por meio da identificação social e representatividade do corpo esportivo de uma nação e, também, pelos valores que o esporte propaga na sociedade.

A escola, enquanto espaço de formação, tem como função social transmitir o saber sistematizado e fornecer acesso as mais distintas áreas do conhecimento. Uma área que tem tido destaque ultimamente é a Educação Física, a qual tem como objeto de estudo o corpo em movimento, possuindo uma função social a cumprir no espaço escolar em toda a Educação Básica, seja na Educação Infantil, Ensino Fundamental ou Ensino Médio.

A área da Educação Física hoje deve assumir o papel que lhe é conferido por diferentes documentos "quanto à sua relevância dentro da estrutura escolar, promovendoo desenvolvimento de diferentes capacidades cognitivas, afetivas, físicas, éticas, estéticas, de inserção social e de relação interpessoal" (BERTINI JUNIOR; TASSONI, 2013, p. 473). 
A Educação Física faz parte da cultura humana, age sobre um conjunto de exercícios relacionados ao corpo e ao movimento inventadas pelo homem ao longo de sua história (ALENCAR et al., 2019). Entre esses exercícios estãoos jogos, as ginásticas, as lutas, as danças e as diferentes modalidades de esportes (BRASIL, 2017), assim, o professor dessa área desempenha uma função privilegiada dentro da escola.

Encontra-se expresso na Constituição Federal que o lazer é um direito de todos, enquanto cidadãos sem distinção de classe social, crença, faixa etária e gênero, desse modo, ele necessita ser exercitado com total liberdade e maior desprendimento possível (BRASIL, 1988). O esporte, tido como uma das atividades de lazer, se constitui em um importante elemento na vida do ser humano, seja para o desenvolvimento corporal, psicológico ou social (VIEIRA; CRUZ, 2014).

A Base Nacional Comum Curricular (BNCC) enfatiza que a prática do esporte, na escola, possibilita a distribuição das modalidades esportivas em categorias de forma a privilegiar as ações motoras intrínsecas, reunindo esportes que apresentam exigências motrizes semelhantes no desenvolvimento de suas práticas. Assim, são apresentadas sete categorias de esportes: marca, precisão, técnico-combinatório, rede/quadra dividida ou parede de rebote, campo e taco, invasão ou territorial e combate (BRASIL, 2017).

O esporte reconhecidamente como uma constituição humana se trata de direito social. No artigo 217, da Constituição Federal Brasileira, o esporte é enfatizado como um direito do cidadão, uma prática cultural que faz parte do dia a dia do homem moderno, sendo "dever do Estado fomentar práticas desportivas formais e não-formais” (BRASIL, 1988, art. 217), prática que precisa ser desenvolvida no campo escolar.

O ensino do esporte na escola deve abranger conhecimentos teóricos e práticos, oferecendo ao aluno a oportunidade de aprender e vivenciar seus fundamentos, compreender suas regras e conhecer sua história e evolução. O indivíduo, em toda sua totalidade, é um ser em movimento, que desde o seu nascimento, corre, brinca, salta, rasteja, realiza movimentos pertinentes que fazem parte de sua formação, realiza movimentos construídos ou de reflexos, e com seu crescimento, esses movimentos aumentam através de brincadeiras e de jogos.

Dessa forma, cabe ao profissional de Educação Física proporcionar aos alunos dentro das atividades propostas movimentos que possam ser assimilados cognitivamente e afetivamente, assegurados para a perfeita formação.

Dentro desse contexto se têm os esportes coletivos que podem ser amplamente explorados, já que podem ser adequados a todas as faixas etárias, além de trabalhar com os alunos a questão do movimento, dos aspectos físicos e emocionais, também é uma excelente forma de promover a inclusão social, tanto fora como dentro da escola. Nesse sentido, o objetivo deste estudo é compreender como a prática esportiva na escola pode contribuir na vida social do aluno.

\section{Desenvolvimento}

\subsection{Metodologia}

Para elaboração deste estudo se utilizou a revisão integrativa da literatura, que consiste em um tipo de revisão de natureza complexa e métodos sistematizados que garantem o rigor requisitado de uma pesquisa científica (SOARES et al., 2014). De acordo com Whittemore e Knafl (2005), a revisão integrativa é composta de cinco etapas, sendo essas: 1) identificação do problema; 2) busca na literatura; 3) avaliação dos dados; 4) análise dos dados; 5) apresentação dos resultados. Como primeira etapa da revisão integrativa, esta pesquisa busca responder à seguinte problemática: comoa prática esportiva na escola pode contribuir na vida social do aluno?

Com o intuito de atender a segunda etapa da revisão integrativa, a mesma foi dividida em duas fases. Na fase primária, alguns critérios de buscas foram adotados: a) utilizou-se as bases de dados Literatura Latino-Americana e do Caribe em Ciências da Saúde (Lilacs), Scientific Electronic Library Online (SciELO), Dialnet e Directory of Open Access Journals (DOAJ); b) como estratégia de busca foram utilizadas as palavras-chave "esporte", "inclusão" e "escola", adotando-se o conector booleano "AND" entre uma palavrachave e outra; c) foram selecionados apenas artigos e papers, que puderam ser acessados na íntegra, gratuitamente, no meio on-line em português e espanhol; d) artigos publicados nos últimos dez anos (2010 a 2020).

$\mathrm{Na}$ fase secundária da busca na literatura, os resumos dos artigos filtrados foram analisados para identificar relações com a problemática do estudo e realizada a leitura do título, palavras-chave e resumo. Foram eliminados os artigos, cujo resumo não apresentou a temática pesquisada e, também, os artigos que foram repetidos, permanecendo apenas um.

Na terceira etapa da revisão integrativa, ou seja, avaliação dos dados, foram identificados os seguintes atributos dos estudos filtrados: base de dados, título, autores, periódico e ano de publicação, objetivo e resultados obtidos.

Pretendeu-se, na quarta etapa, compreender de que forma a prática esportiva pode ou está contribuindo, socialmente, na vida do aluno de acordo com a literatura encontrada e, dessa forma, o objetivo deste estudo foi atendido.

$\mathrm{Na}$ quinta e última etapa da revisão integrativa, como resultado do estudo, um quadro síntese dos atributos encontrados foi apresentado na busca por atender a problemática da pesquisa.

\subsection{Resultados das buscas}

\subsubsection{Caracterização da amostra}

No total, foram encontrados 47 artigos nas buscas dentro das bases de dados, sendo: Lilacs (8 artigos), ScieELO (6 
artigos), Dialnet (14 artigos) e DOAJ (19 artigos). Desses estudos, foram selecionados 17 artigos para leitura na íntegra, entre os quais cinco pesquisas foram excluídas por não atenderem a temática estudada e dois artigos repetidos, resultando em uma amostra final de 10 artigos.

\subsubsection{Avaliação dos artigos}

Entre os 10 artigos que compuseram esta revisão foram identificados os seguintes atributos: base de dados, título, autores, periódico e ano de publicação, objetivo e resultados obtidos (Quadro 1).

Quadro 1 - Características dos estudos selecionados

\begin{tabular}{|c|c|c|c|c|}
\hline 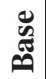 & Título e Autores & Periódico e Ano & Objetivo & Resultados obtidos \\
\hline 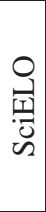 & $\begin{array}{l}\text { O esporte e o Ensino } \\
\text { Médio: a visão dos } \\
\text { professores de Educação } \\
\text { Física da rede pública. } \\
\text { - Santos e Piccolo. }\end{array}$ & $\begin{array}{l}\text { Revista Brasileira } \\
\text { de Educação Física } \\
\text { e Esporte, } 2011 .\end{array}$ & $\begin{array}{l}\text { - Investigar a visão dos } \\
\text { professores de Educação } \\
\text { Física do Ensino Médio } \\
\text { sobre o fenômeno Esporte e } \\
\text { sua relação com a Educação } \\
\text { Física. }\end{array}$ & $\begin{array}{l}\text { - O Esporte aparece como o principal } \\
\text { conteúdo e baseado em modelos } \\
\text { esportivizados, tecnicistas visando } \\
\text { performance, rendimento, aptidão física. }\end{array}$ \\
\hline$\frac{\tilde{c}}{3}:$ & $\begin{array}{l}\text { O Esporte educacional } \\
\text { como tema da } \\
\text { produção de } \\
\text { conhecimento no } \\
\text { periodismo científico } \\
\text { brasileiro: uma revisão } \\
\text { sistemática. } \\
\text { Reis et al. }\end{array}$ & $\begin{array}{l}\text { Revista Pensar a } \\
\text { Prática, } 2015 .\end{array}$ & $\begin{array}{l}\text { - Conhecer a discussão em } \\
\text { torno do esporte educacional } \\
\text { presente na produção } \\
\text { científica da Educação } \\
\text { Física/Ciências do Esporte, } \\
\text { particularmente, àquela } \\
\text { divulgada no periodismo } \\
\text { científico brasileiro. }\end{array}$ & $\begin{array}{l}\text { - Apesar da pouca literatura, os diferentes } \\
\text { tipos de artigos que têm o esporte } \\
\text { educacional como problemática parecem } \\
\text { acompanhar o amadurecimento teórico } \\
\text { da área representando a apropriação } \\
\text { da formatação e do arcabouço teórico- } \\
\text { metodológico de áreas com maior tradição } \\
\text { na pesquisa científica. }\end{array}$ \\
\hline 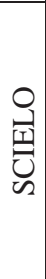 & $\begin{array}{l}\text { Atendimento especializado } \\
\text { em esporte adaptado: } \\
\text { discutindo a iniciação } \\
\text { esportiva sob a ótica da } \\
\text { inclusão. } \\
\text { Beltrame e Sampaio. }\end{array}$ & $\begin{array}{l}\text { Revista de } \\
\text { Educação Física da } \\
\text { UEM, } 2015 .\end{array}$ & $\begin{array}{l}\text { - Analisar e discutir, a } \\
\text { partir da percepção de seus } \\
\text { professores, se o Centro e } \\
\text { Iniciação Paralímpica (CID- } \\
\text { PL) atende aos referenciais } \\
\text { de uma proposta de educação } \\
\text { inclusiva. }\end{array}$ & $\begin{array}{l}\text { - Os resultados das práticas esportivas } \\
\text { são controversos, na medida em que seus } \\
\text { objetivos convergem para a competição e } \\
\text { alto rendimento e pouco se direcionam para } \\
\text { uma prática educativa inclusiva. } \\
\text { - O projeto CID-PL está distante do } \\
\text { propósito da educação inclusiva, embora } \\
\text { parte de suas práticas não as negue. }\end{array}$ \\
\hline 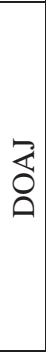 & $\begin{array}{l}\text { A inclusão social através } \\
\text { do esporte: a percepção } \\
\text { dos educadores. } \\
\text { Vianna e Lovisolo. }\end{array}$ & $\begin{array}{l}\text { Revista Brasileira } \\
\text { de Educação Física } \\
\text { e Esporte, } 2011 .\end{array}$ & $\begin{array}{l}\text { - Identificar as regularidades } \\
\text { e as particularidades na } \\
\text { percepção de professores de } \\
\text { educação física, que atuam } \\
\text { em projetos de inserção } \\
\text { social através do esporte em } \\
\text { comunidades populares do } \\
\text { município do Rio de Janeiro, } \\
\text { sobre os seus alunos e a } \\
\text { intervenção institucional. }\end{array}$ & $\begin{array}{l}\text { - Os professores não conseguem perceber } \\
\text { em seus alunos potenciais para crescerem no } \\
\text { esporte. } \\
\text { - Não acreditam no esporte como meio de } \\
\text { formação pessoal e profissional. } \\
\text { - Não percebem em si competência para } \\
\text { contribuir na formação dos alunos } \\
\text { - Não estão comprometidos com o processo } \\
\text { de formação dos alunos. }\end{array}$ \\
\hline 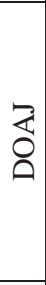 & $\begin{array}{l}\text { Desenho da rede de um } \\
\text { projeto esportivo social: } \\
\text { atores, representações e } \\
\text { significados. } \\
\text { Silva e Silva. }\end{array}$ & $\begin{array}{l}\text { Revista Brasileira } \\
\text { de Educação Física } \\
\text { e Esporte, } 2014 .\end{array}$ & $\begin{array}{l}\text { - Explorar os sentidos e } \\
\text { significados atribuídos } \\
\text { pelos atores de uma rede } \\
\text { que desenvolve um projeto } \\
\text { esportivo social. }\end{array}$ & $\begin{array}{l}\text { - As percepções dos atores circulam pelas } \\
\text { ideias de que o projeto "muda a vida das } \\
\text { pessoas", que os jovens "tornam-se menos } \\
\text { agressivos", que há "contribuição na } \\
\text { formação social das crianças, jovens e das } \\
\text { famílias" e que promove a "inclusão social } \\
\text { de pessoas que vivem em comunidades } \\
\text { pobres. }\end{array}$ \\
\hline 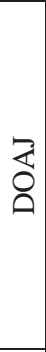 & $\begin{array}{l}\text { Programas sociais de } \\
\text { esporte e lazer na escola } \\
\text { e na comunidade: as } \\
\text { evidências de exclusão } \\
\text { social e educacional na } \\
\text { sociedade brasileira. } \\
\text {-Taffarel. }\end{array}$ & $\begin{array}{l}\text { Revista } \\
\text { Motrivivência, } 2012\end{array}$ & $\begin{array}{l}\text { - Discutir indicadores das } \\
\text { avaliações educacionais } \\
\text { e as reivindicações dos } \\
\text { trabalhadores e, um programa } \\
\text { de transição na perspectiva da } \\
\text { alternativa de projeto histórico } \\
\text { para além do capital. }\end{array}$ & $\begin{array}{l}\text { - A educação e o esporte por si só não tem } \\
\text { como enfrentar as contradições de um } \\
\text { sistema que determina quem é incluído ou } \\
\text { excluído da classe burguesa. } \\
\text { - Ou a educação e o esporte se sintonizam } \\
\text { com a revolução no contexto de resistência } \\
\text { e de luta concreta pela transformação no } \\
\text { sentido socialista ou continuará discursando } \\
\text { sobre a sua capacidade de inclusão que é } \\
\text { aparente e só aparente. }\end{array}$ \\
\hline 㫐 & $\begin{array}{l}\text { A iniciação do futsal } \\
\text { nas escolas de Ensino } \\
\text { Fundamental II em Monte } \\
\text { Alto-SP. } \\
\text { Zambon e Bolsonaro. }\end{array}$ & $\begin{array}{l}\text { Revista Brasileira } \\
\text { de Futsal e Futebol, } \\
2016 .\end{array}$ & $\begin{array}{l}\text { - Analisar como é estruturada } \\
\text { a iniciação do Futsal nas } \\
\text { escolas de ensino fundamental } \\
\text { II no município de Monte } \\
\text { Alto-SP. }\end{array}$ & $\begin{array}{l}\text { - } 78 \% \text { dos professores aplicam em suas aulas } \\
\text { de iniciação do Futsal um método misto } \\
\text { entre Global e Analítico, enquanto apenas } \\
\text { dois professores preferem empregar em suas } \\
\text { aulas apenas um dos métodos; um preferindo } \\
\text { o método Global e o outro o método } \\
\text { Analítico. }\end{array}$ \\
\hline
\end{tabular}




\begin{tabular}{|c|c|c|c|c|}
\hline 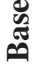 & Título e Autores & Periódico e Ano & Objetivo & Resultados obtidos \\
\hline 㫐 & $\begin{array}{l}\text { Esporte paralímpico: } \\
\text { difícil inclusão, } \\
\text { incorporação tecnológica, } \\
\text { corpos } \\
\text { Competitivos. } \\
\text { Torri e Vaz. }\end{array}$ & $\begin{array}{l}\text { Revista Práxis } \\
\text { Educativa, } 2017 .\end{array}$ & $\begin{array}{l}\text { - Analisar o esporte em sua } \\
\text { versão paraolímpica, com foco } \\
\text { nos discursos que valorizam } \\
\text { práticas que seriam de } \\
\text { superação e inclusão, tomando } \\
\text { como situações exemplares } \\
\text { algumas representações sobre } \\
\text { o fenômeno. Desenvolvendo } \\
\text { dois tópicos: rendimento X } \\
\text { estética } \\
\text { e aproximação entre o esporte } \\
\text { olímpico e paralímpico. }\end{array}$ & $\begin{array}{l}\text { - Dificilmente esses competidores são em } \\
\text { primeiro lugar lembrados como atletas, } \\
\text { como foi possível verificar na fala da atleta } \\
\text { Rosinha dos Santos do atletismo do Brasil, } \\
\text { antes sim como deficientes. } \\
\text { - Segundo o modelo que ainda impera, } \\
\text { apenas como tais que devem ser observados, } \\
\text { produzir beleza, angariar reconhecimento. }\end{array}$ \\
\hline 㫐 & $\begin{array}{l}\text { A reorientação da ação } \\
\text { pedagógica na Educação } \\
\text { Física sob a perspectiva da } \\
\text { inclusão: a pesquisa-ação } \\
\text { como caminho. } \\
\text { Souza e Pich. }\end{array}$ & $\begin{array}{l}\text { Revista Movimento, } \\
2013 .\end{array}$ & $\begin{array}{l}\text { - Orientar o processo de } \\
\text { reconstrução das práticas } \\
\text { pedagógicas do professor na } \\
\text { implantação da Educação } \\
\text { Física inclusiva. }\end{array}$ & $\begin{array}{l}\text { - Houve um processo de reflexão-ação por } \\
\text { parte dos professores que começaram a } \\
\text { mudar aspectos de sua prática com inserções } \\
\text { de procedimentos para a inclusão nas suas } \\
\text { aulas. } \\
\text { - Não é possível dimensionar se as } \\
\text { conquistas garantem a legitimação da } \\
\text { concepção inclusiva de forma permanente. }\end{array}$ \\
\hline 㫐 & $\begin{array}{l}\text { O judô nas escolas: do } \\
\text { método tradicional à } \\
\text { prática transformadora } \\
\text { como conteúdo da } \\
\text { Educação Física. } \\
\text { Ferreira. }\end{array}$ & $\begin{array}{l}\text { Revista Lecturas: } \\
\text { Educación Física y } \\
\text { Deportes, } 2019 .\end{array}$ & $\begin{array}{l}\text { - Apontar a importância da } \\
\text { inclusão do judô nas aulas de } \\
\text { Educação Física escolar para } \\
\text { um melhor desenvolvimento } \\
\text { social e, relatar sobre os } \\
\text { benefícios que o judô, como } \\
\text { conteúdo da Educação Física, } \\
\text { proporciona às crianças. }\end{array}$ & $\begin{array}{l}\text { - A prática esportiva do judô tem o seu valor } \\
\text { educativo, mas cabe ao professor repensar } \\
\text { as questões de cidadania, ludicidade, } \\
\text { afetividade, liberdade de expressão e o } \\
\text { prazer. }\end{array}$ \\
\hline
\end{tabular}

Fonte: os autores.

\subsection{Discussão}

\subsubsection{O esporte como forma de inclusão e transformação social}

Em uma investigação mais aprofundada dos artigos selecionados pela revisão integrativa, $60 \%$ dos artigos $(n=6)$ abordaram o esporte sob o ângulo da inclusão, 20\% ( $\mathrm{n}=2)$ abordaram apenas indiretamente, ou seja, o texto até citou, mas não discorreu a respeito e, $20 \%(n=2)$ não abordaram de forma nenhuma a temática, embora tenham passado pelos critérios iniciais do filtro.

Beltrame e Sampaio (2015), em sua pesquisa, intitulada "Atendimento especializado em esporte adaptado, discutindo a iniciação esportiva sob a ótica da inclusão", teve por objetivo analisar, a partir da percepção de seus professores, se o Centro de Iniciação Paralímpica (CID-PL) atende aos referenciais de uma proposta de educação inclusiva. Os autores discorrem sobre uma importante reflexão, no que diz respeito às práticas pedagógicas com abordagens arrojadas e criativas para a formação do indivíduo.

Nesse sentido, ressignificar práticas esportivas e desmistificar o senso comum que vincula o esporte ao alto rendimento é essencial, pois desconstrói a ideia de que o esporte é apenas aprendizagem de movimentos sistematizados, o qual se destacam apenas os mais aptos. Os autores concluíram que embora o CID-PL tenha uma proposta inclusiva, de acordo com relatos de seus professores, há um forte indício indo em direção à competição e ao alto rendimento, apresentando assim uma lacuna no que concerne à inclusão, visto quea educação inclusiva que se pretende deve ser pautada em um aprendizado atrativo para esse público que almeja pelo conhecimento independente de vitórias ou insucessos (BELTRAME; SAMPAIO, 2015).

Nessa direção, Tubino (2011), quando aborda sobre a dimensão social do esporte-performance, afirma que esse é relevante pelo efeito que produz sobre a sociedade, porém o espetáculo dessa modalidade esportiva proporciona uma série de possibilidades sociais, tanto positivas quanto negativas.

Tendo por objetivo identificar as particularidades, na percepção de professores de Educação Física, atuantesem projetos sociais, por meio do esporte em comunidades populares do Rio de Janeiro, sobre seus alunos e a intervenção institucional, o estudo de Vianna e Lovisolo (2011) abordou os entendimentos referentes à inclusão social através do esporte. De acordo com o perfil das respostas e baseados nos discursos adotados pelos professores investigados, os pesquisadores chegaram à conclusão de que os educadores desse projeto não acreditam na inclusão por meio do esporte.

Ressalta-se que existem defensores do esporte como meio de inclusão social, mas existem também críticas a este respeito. Adversa a esta ideia se tem muitos estudos, que defendem e afirmam por meio de pesquisas os benefícios dos esportes tanto para a melhora da qualidade de vida dos participantes como para a formação social dos mesmos (VIANNA; LOVISOLO, 2011).

O Projeto Boxe Vidigal (PBV) foi o objeto de estudo, 
que Silva e Silva (2014) tiveram como objetivo exploraros significados atribuídos pelos atores de uma rede, que desenvolve um projeto esportivo social. Os entendimentos de que o projeto muda a vida das pessoas diminuindo o índice de violência, que contribui na formação dos alunos estendendose às famílias e que promove a inclusão de pessoas, que vivem em comunidades menos favorecidas, foi o resultado encontrado pelos autores, notando dessa maneira, o impacto positivo causado pelo esporte.

A percepção do esporte como meio de socialização positiva ou inclusão social é percebido pelo aumento da quantidade de projetos esportivos destinados aos jovens das classes populares, que são patrocinados por instituições governamentais e não governamentais. Como exemplo setêm os programas alternativos paralelos à educação formal, voltados normalmente para a iniciação profissional e educação por meio do esporte e do trabalho, que foram implantados, principalmente, a partir da década de 1980, em oposição a socialização desempenhada pelo crime organizado em favelas, o que mostra que o esporte surge como atividade alternativa dominante à rua (VIANNA; LOVISOLO, 2011).

O estudo de Torri e Vaz (2017) analisou aspectos da versão paraolímpica do esporte enfatizando argumentos que valorizam práticas de superação e de inclusão, abrangendo como situações exemplares algumas representações sobre o fenômeno. Após investigarem, os autores, baseados nas análises dos discursos, constataram que é improvávelos competidores serem vistos como atletas, e sim, como deficientes.

A sensibilização do professor sobre a prática pedagógica inclusiva na Educação Física escolar é um processo de reflexãoação por parte dos professores, que começaram a mudar aspectos de sua prática com inserções de procedimentos para a inclusão do aluno com deficiência em suas aulas. Esses foram os resultados apresentados por Souza e Pich (2013), embora seja apontada a dúvida em mensurar se essas conquistas garantem a legitimação dessas concepções inclusivas em uma configuração constante.

Nesse cenário, a Educação Física Escolar deve estabelecer um reposicionamento na produção dos conhecimentos curriculares, de forma articulada, com a produção dos saberes docentes, a partir do lado de dentro dos muros da escola (FERRAZ; CORREIA, 2012).

Ferreira (2019) apresenta evidências, por meio dos resultados examinados, em sua pesquisa, dos benefícios que o esporte proporciona no contexto escolar, por meio da modalidade Judô. A importância da inclusão do judô, nas aulas de Educação Física escolar, para um avanço social e relatar os benefícios que esta arte marcial proporciona aos alunos foram os objetivos do autor. Mesmo ao constatar que essa prática esportiva tem impactos significativos no ambiente escolar, o autor destaca que o educador tem relação direta na formação dos alunos, pois é ele que exerce o papel de mediador neste processo.

Para Maia (2010), o esporte inserido no ambiente escolar não deve ser voltado para a competição, esse deve possuir um sentido distinto, no qual o educando possa desenvolver um posicionamento crítico e sua prática deve considerar suas reais características e não simplesmente o realize de maneira mecânica ou visando a competitividade. $\mathrm{O}$ esporte deve servir para formar o indivíduo para atuação direta na sociedade em que se encontra inserido, desenvolver experiências grupais, mecanismos individuais de autocontrole, de habilidades físicas, cognitivas, valorização das relações interpessoais, construção de hábitos e valores para a vida social, resistência à frustração e aceitação dos princípios e tarefas do grupo social, prática da solidariedade, cooperação e participação proativa.

Seja qual for a modalidade, a prática esportiva se sobressai por promover a interação, proporcionar às crianças novas amizades, enfrentar desafios e estimular o espírito de superação, entre tantas outras variáveis. No ambiente escolar, esse apelo é ainda mais forte, pois é na escola que os alunos passam seu maior tempo e o educador tem a oportunidade de exercer seu papel de maneira comprometida.

\subsubsection{Contribuiçoes futuras dos estudos investigados}

Como contribuições futuras, os estudiosos dos artigos investigados sugeriram algumas pesquisas. Beltrame e Sampaio (2015) elencaram sobre a necessidade de as discussões avançarem para além dos resultados, destacaram que ainda predominam ações voltadas para o esporte de alto rendimento em detrimento das práticas voltadas para o esporte educacional e participativo. Desse modo, pensando em uma cultura inclusiva é essencial que o professor permita a vivência do lúdico, que merece maior destaque em outros estudos, que tenciona a favor da interação com a criança, superando a mesmice de modelos preestabelecidos.

Neste contexto, ainda que haja benefícios em torno do esporte competição, cabe ao professor orientar o aluno e desconstruir o conceito equivocado de que apenas os mais talentosos é que são aceitos. Tubino (2011) evidencia este fato ao mencionar que o principal equívoco histórico do esporte educação é o entendimento de que esse se constitui em um ramo do esporte de rendimento, dessa forma, as competições escolares que deveriam estar voltadas para o processo educativo acabam se tornando competições.

A educação, por ter uma finalidade social, deve necessariamente trabalhar com o esporte-educação conteúdos educativos. Sendo assim, uma orientação educativa no esporte precisa trabalhar as três áreas de atuação pedagógica: integração social, desenvolvimento psicomotor e atividades físicas educativas (TUBINO, 2011).

Em relação à análise desempenhada por Vianna e Lovisolo (2011), os autores sugerem que os indicativos apontados, ainda que de maneira negativa, merecem ser mais investigados, 
pois o seu resultado parece ser a falta de instrumentalização dos alunos participantes em projetos de inclusão social para que tenham condições de fazer maiores investimentos na formação esportiva.

Silva e Silva (2014) propõem, em seu artigo, que seja efetivada uma aproximação da rede do projeto esportivo social com alguma Universidade, ampliando assim as possibilidades de crescimento, auxiliando em questões relativas às legislações de incentivo ao esporte, elaboração de um site pela área de comunicação, entre outras ações, descentralizando as tarefas na pessoa de seu idealizador e coordenador que pode, no futuro, inviabilizar o próprio projeto pela falta de novas lideranças.

O estudo desenvolvido por Torri e Vaz (2017) trouxe como possíveis colaborações a proposta de produzir umaoutra narrativa sobre o esporte paraolímpico e seus atletas, apontando caminhos ainda pouco percorridos na análise do fenômeno e alguns planos, em que o esporte paraolímpico (e também o olímpico) pode se colocar como expressão social de nosso tempo.

No artigo de Souza e Pich (2013), os autores apontam a necessidade de novas pesquisas sociais para subsidiar o desenvolvimento da reorientação das diretrizes pedagógicas para a Educação Física escolar na rede escolar, em particular no que diz respeito ao sistema de avaliação, na gestão do trabalho na área da educação escolar inclusiva e na reversão do estigma do aluno com deficiência.

No que concerne à prática do judô na escola, Ferreira (2019) elenca que a modalidade fundamentada em uma pedagogia transformadora deixa de ser apenas uma prática incluída nos estabelecimentos de ensino para se tornar um conteúdo e um meio para atingir objetivos e mudanças de vertentes na formação do educando. Deixa sua pesquisa como uma motivação para novos estudos, notando que ainda há muitos assuntos, que permeiam a inclusão para intencionála concluída, desse modo, como um início de um novo combate, no que tange aos estudos acadêmicos sobre a prática pedagógica do judô no ambiente educativo.

Em se tratando do esporte na escola, ressalta-se a importância das aulas de Educação Física, pois as crianças se encontram confinadas, em sala de aula, a maior parte do tempo, ocupando-se de outras disciplinas, muitas vezes, sem poder se movimentar pela sala de aula. Diante disso, deve haver um engajamento, por parte do profissional de Educação Física, proporcionando aos alunos movimentos que possam ser assimilados cognitiva e afetivamente, garantindo uma boa formação, fato que torna a intervenção do educador essencial.

Cortês Neto, Dantas e Maia (2015) destacam que o esporte proporciona o sentimento de pertencimento e suas particularidades, como ligações de amizade, busca por objetivos comuns, responsabilidades, sentimento de apoio e de cooperação entre os jovens, obtenção de maior força de representatividade na comunidade. Assim como valores e atitudes positivas desenvolvidas, por meio da prática esportiva, tem sido observado como impulsionadores de melhora de comportamento no cotidiano, no ambiente familiar e também na escola.

\section{Conclusão}

O propósito deste estudo foi analisar como a prática esportiva na escola pode contribuir na vida social do aluno e, embora tenha sido encontrado um número satisfatório de artigos para compor esta pesquisa, ainda são poucos os estudos que tratam sobre a inclusão, por meio do esporte, mesmo que este instrumento se apresente como uma valiosa ferramenta na educação.

Ainda assim, observou-se que há um consenso entre os autores ao discursar sobre a contribuição que o esporte desempenha na vida das crianças, entretanto, para que o educando possa ter autonomia e uma visão crítica é imprescindível a intervenção do professor. Esta prática deve oferecer meios que oportunizem a esses alunos uma interação social e, assim, possa levá-los a uma reflexão para enfrentar e superar os desafios que a vida propõe.

É indispensável a discussão de práticas pedagógicas com perspectivas inovadoras que levem, tanto os professores como toda equipe pedagógica, a repensar o esporte como instrumento de formação e não apenas pautado na execução de técnicas perfeitas. Em uma época marcada pela insegurança e instabilidade, na qual as pessoas precisam ser decididas e autônomas para viver em sociedade, é desafiador e necessário uma educação que seja de fato includente.

Como principais contribuições se sugere que pesquisas futuras possam partir para o campo da mensuração para complementar as conclusões qualitativas observadas nos estudos. Outra contribuição importante é conduzir os estudiosos a refletirem sobre a relevância em continuar a investigação sobre essa temática, já que esta discussão está longe de ser esgotada.

\section{Referências}

ALENCAR, G.P. et al. A corporeidade e suas relações com a Educação Física escolar. Rev Lecturas Educ. Fís. Deportes, v.24, n.252, p.154-164, 2019.

BELTRAME, A.L.N.; SAMPAIO, T.M.V. Atendimento especializado em esporte adaptado: Discutindo a iniciação esportiva sob a ótica da inclusão. Rev. Educ. Fís. UEM, v.26, n.3, p.377-388, 2015. doi: http://dx.doi.org/10.4025/reveducfis. v26i3.24990

BERTINI JUNIOR, N.; TASSONI, E.C.M. A Educação Física, o docente e a escola: concepções e práticas pedagógicas. Rev Bras. Educ. Fís. Esp., v.27, n.3, p.467-83, 2013. doi: http://dx.doi. org/10.1590/S1807-55092013000300013

BRASIL. Constituição da República Federativa do Brasil. Brasília: Senado Federal, 1988.

BRASIL. Ministério da Educação. Base Nacional Comum Curricular: Educação é a Base. Brasília, MEC/CONSED/ UNDIME, 2017.

CORTÊS NETO, E.D.; DANTAS, M.M.C.; MAIA, E.M. C. Benefícios dos projetos sociais esportivos em crianças e 
adolescentes. Saúde Transf. Soc., v.6, n.3, p.109-117, 2015.

FERRAZ, O.L.; CORREIA, W.R. Teorias curriculares, perspectivas teóricas em Educação Física Escolar e implicações para a formação docente. Rev Bras. Educ. Fís. Esporte, v.26, n.3, p.531-540, 2012. doi: https://doi.org/10.1590/S180755092012000300018

FERREIRA, J.E.R. O judô nas escolas: do método tradicional à prática transformadora como conteúdo da Educação Física. Rev. Lecturas Educ. Fís. Deportes, v.24, n.253, p.1-13, 2019.

MAIA, M.M.O. Dimensões sociais do esporte: perspectivas trabalhadas nas escolas da cidade de Pau dos Ferros, RN. Rev. Lecturas Educ. Fís. Deportes, v.15, n. 144, p. 1-7, 2010.

REIS, N.S. et al. O esporte educacional como tema da produção de conhecimento no periodismo científico brasileiro: uma revisão Sistemática. Rev Pensar Prática, v.18, n.3, p.709-724. doi: https:// doi.org/10.5216/rpp.v18i3.34326

SANTOS, M.A.G.N.; PICCOLO, V.L.N. O esporte e o ensino médio: a visão dos professores de educação física da rede pública. Rev Bras. Educ. Fís. Esporte, v.25, n.1, p.65-78, 2011. doi: http:// dx.doi.org/10.1590/S1807-55092011000100008

SILVA, O.M.; SILVA, C.A.F. Desenho da rede de um projeto esportivo social: atores, representações e significados. Rev Bras. Educ. Fís. Esporte, v.28, n.3, p.415-428, 2014. doi: https://doi. org/10.1590/1807-55092014000300415

SOARES, C.B. et al. Revisão integrativa: conceitos e métodos utilizados na enfermagem. Rev Esc. Enferm. USP, v.48,n.2, p.335-345, 2014. doi: https://doi.org/10.1590/S00806234201400002000020
SOUZA, G. C.; PICH, S. A reorientação da ação pedagógica na Educação Física sob a perspectiva da inclusão: a pesquisaação como caminho. Rev Mov., v.19, n.3, p.149-169, 2013. doi: https://doi.org/10.22456/1982-8918.35851

TAFFAREL, C. Z. Programas sociais de esporte e lazer na escola e na comunidade: as evidências de exclusão social e educacional na sociedade brasileira. Rev Motriv., v.24, n.38, p.135-148, 2012. doi: https://doi.org/10.5007/2175-8042.2012v24n38p135

TORRI, D.; VAZ, A.F. Esporte paraolímpico: difícil inclusão, incorporação tecnológica, corpos competitivos. Rev Práxis Educ., v.12, n.2, p.536-550, 2017. doi: https://doi.org/10.5212/ PraxEduc.v.12i2.0014

TUBINO, J. G. Dimensões sociais do esporte. São Paulo: Cortez, 2011.

VIANNA, J.A.; LOVISOLO, H.R. A inclusão social através do esporte: a percepção dos educadores. Rev. Bras. Educ. Física Esporte, v.25, n.2, p.285-296, 2011. doi: https://doi.org/10.1590/ S1807-55092011000200010

VIEIRA, M. B.; CRUZ, N. G. Corporeidade, ludicidade, mediação docente. Rev. Lecturas Educ. Fís. Deportes, v. 19, n.196, p.1-7, 2014.

WHITTEMORE, R.; KNAFL, K. The integrative review:updated methodology. J. Adv. Nurs., v.52, n.5, p.546-553, 2005. doi: https://doi.org/10.1111/j.1365-2648.2005.03621.x

ZAMBON, S.G.; BOLSONARO, J.R. A iniciação do futsal nas escolas de Ensino Fundamental II em Monte Alto-SP. Rev. Bras. Futsal Futebol, v.8, n.31, p.326-333, 2016. 